\title{
Age Estimation of Roundnose Grenadier (Coryphaenoides rupestris), Effects of Uncertainties on Ages
}

\author{
P. Lorance ${ }^{1}$ and F. Garren \\ IFREMER, 150 quai Gambetta, BP 699, 62321 Boulogne-sur-mer, France \\ J. Vigneau \\ IFREMER, av. du Général de Gaulle, BP 32, 14520 Port-en Bessin, France
}

\begin{abstract}
For the roundnose grenadier (Coryphaenoides rupestris), one of the larger macrourid species exploited at the upper and mid-slope depth in the North Atlantic, the reading scheme of the otoliths is quite easily agreed upon by most workers, and the readings are in acceptable agreement with age validation formerly obtained on the juveniles. In the North East Atlantic, the roundnose grenadier fishery operates over large areas and does not target concentrations of pure adult fish, unlike some other deep-water fisheries. The changes in the age compositions of the exploited populations are likely to appear in the catch and changes in the length distribution of the landings have appeared since the onset of fishing.

In the present paper the growth of the roundnose grenadier from the west of British Isles is investigated from age readings of otoliths collected in 1996 and 1999. Age readings are made from 923 otoliths and compared to pre anal fin length (PAFL) measurements. The observed growth is adjusted to the Von Bertalanffy growth model (VBGM) and the difference in the estimated growth parameters according to the method used to fit the model is explored. The sexual dimorphism in growth is investigated and the implications of the uncertainties in growth and age estimations for the assessment and for ecological studies are discussed. The results show that age uncertainties cannot be disregarded and the usefulness of such parameters for assessment purposes is discussed. The relationships between length, age and otolith weight were analysed and the otolith weight appeared as a possible alternative solution to estimate the age of the roundnose grenadier.
\end{abstract}

Key words: age, Coryphaenoides rupestris, grenadier, growth, length, otoliths, North Atlantic

\section{Introduction}

The estimation of the age composition of the catch is a prerequisite for the accurate analytical assessment of exploited fish resources. However, most deep-water fish stocks are assessed or managed with the lack of age structure information. The roundnose grenadier (Coryphaenoides rupestris) is one of the major deepwater species exploited in the northeastern Atlantic. Although the potential interest for fisheries of this species was first noticed more than 20 years ago (Bridger, 1978; Ehrich, 1983), the exploitation did not start before the late-1980s when French trawlers began to fish deeper along the slope to the west of the British isles and south of Faeroe Islands (Charuau et $a l ., 1995)$. The roundnose grenadier is now the most abundant species in the landings of the French deepwater fleet. The French exploitation has mainly developed to the west of Scotland (ICES sub-area VI). In the ICES region, it is also exploited by Denmark and Norway in the Skagerrak (ICES sub-area III) and, to a lesser extent by Iceland and Faeroe Islands mainly in their respective surrounding waters and by Scotland in ICES sub-area VI. Lastly the catch has strongly increased in recent years in ICES sub-area XII due to a developing exploitation from Spanish trawlers (Durán Muñoz and Román, MS 2001).

Before exploitation in the northeastern Atlantic, the species was exploited in the northwestern Atlantic and on the Mid-Atlantic Ridge starting in the late1960s (Atkinson, 1995; Troyanovsky and Lisovsky, 1995). The biology of the species is quite well described; its reproduction was the subject of several studies as well as its distribution and some aspects of its ecology (Allain, 1999; Allain, 2001; Atkinson,

1 Current address: IFREMER, BP 70, 29280 Plouzané, France 
1995; Bergstad, 1990; Gordon, 1979; Haedrich and Merrett, 1988; Kelly et al., 1996, 1997; Mauchline and Gordon, 1984). However, the stocks and population identities are as yet unknown and the areas used as stock units for stock assessment purposes are based upon hydrological hypotheses (Anon., MS 2000).

In respect of assessment methods of deep-water species, age- and length-based methods are seldom used (Large et al., 2003). They seem questionable for some species. However, growth parameters are necessary for some assessment models and their spatial and temporal variations may indicate distinct populations and effect of fishing pressure respectively. The most studied case using these methods is that of orange roughy (Hoplostethus atlanticus) for which the length distribution of the catch changed little after 20 years of exploitation (Clark, 2001; Clark et al., 2000). This may be due to several factors including episodic recruitment and the distribution of the populations in discrete aggregations of adult fish that the fishery may deplete sequentially (Koslow et al., 2000). In the Southwest Pacific, orange roughy, is assessed from stock reduction models using both fishery and survey data (Annala et al., MS 2002). Although there is a general agreement that orange roughy is one of the longest lived exploited fish species (Tracey and Horn, 1999), age estimates are still subject to debate and age validation data remain limited.

On the other hand, life history and energetics of roundnose grenadier are very different from that of orange roughy (Koslow, 1996). It has a dispersed geographical distribution contrasting with the aggregating one of orange roughy and the length distribution of landed fish progressively changed since the start of the exploitation (Anon., MS 2000). The annual periodicity of the annuli read on otoliths was validated for juveniles up to the age of 8 (Gordon and Swan, 1996). Although this validation in only partial (Beamish and McFarlane, 1983), the growth rate of the juveniles in the range of the validated ages is consistent with that inferred from otolith readings of larger fish. The pattern of growth increments seems also very similar to that of the pacific grenadier (Coryphaenoides acrolepis) that grow to similar sizes and ages (see Fig. 2 in Andrews et al., 1999), which was radiometrically validated (Andrews et al., 1999). Therefore, age- and length-based assessment methods seem more relevant to roundnose grenadier than to orange roughy. The hypothesis from Bergstad (1990) that the zones laid down on the surface of the otoliths represent annual growth increments seems the most likely.

The most recent assessment of roundnose grenadier in the ICES region was based upon commercial catch CPUE using surplus production and modified DeLury models (Large et al., 2003; Anon., MS 2000). Preliminary aged-based assessments were also tried (Anon., MS 1998; Lorance et al., 2001) and growth and mortality parameters were used for the calculation of maximum sustainable yield (MSY) from the Beddington and Cooke procedure (Beddington and Cooke, 1983). Age structures were formerly estimated for the (assumed) population of the Skagerrak, in the North Sea (Bergstad, 1990) and for the west of the British Isles (Kelly et al., 1997; Lorance et al., 2001).

In the present paper the growth of the roundnose grenadier from the west of British Isles is investigated from age readings of otoliths collected in 1996 and 1999. The observed growth is adjusted to the Von Bertalanffy growth model (VBGM) and the difference in the estimated growth parameters according to the method used to fit the model is explored. The sexual dimorphism in growth is investigated and the implications of the uncertainties in growth and age estimations for the assessment and for ecological studies are discussed. An alternative to otolith readings for age estimation is suggested but will require further research before being used for assessment purposes.

\section{Materials and Methods}

\section{Sampling}

The otoliths were collected during two deep-water trawling cruises of the French $R / V$ Thalassa in 1996 and 1999. On board, both sagittal otoliths were removed and stored in paper envelopes. The pre-anal fin length (PAFL), from the tip of the snout to the first anal fin spine, was recorded to the lowest $1 / 2 \mathrm{~cm}$ together with the sex and total weight to the nearest $10 \mathrm{~g}$ of the fish.

Most of the otoliths $(n=725)$ used here were collected in 1999 from the catch of a large commercial bottom otter trawl at depths of 1000 to $1300 \mathrm{~m}$ in two sampling areas: (i) the west of Brittany at about $48^{\circ} \mathrm{N}$ and $8^{\circ} 30^{\prime} \mathrm{W}$ and (ii) the west of the British Isles from $54^{\circ} 30^{\prime} \mathrm{N}$ to $56^{\circ} 40^{\prime} \mathrm{N}$ and from $9^{\circ} 30^{\prime} \mathrm{W}$ to $11^{\circ} 25^{\prime} \mathrm{W}$ to the east of the Rockall Trough. This data set was completed with 228 otoliths taken from the collection 
of a cruise carried out in 1996. These were mainly otoliths of juvenile individuals $(n=195)$ of less than $10 \mathrm{~cm}$ PAFL, which were few in the 1999 sampling. The sampling area was the same as in 1999 to the west of the British Isles and the depth range was slightly greater, from $990 \mathrm{~m}$ to $1400 \mathrm{~m}$. Some small fish were also taken with a $6 \mathrm{~m}$ beam trawl used to sample the benthic fauna (Godart, MS 1997). Due to this combination of two different years, the data may not be suitable for constructing an age-length key for assessment, but this is not a problem for growth estimation.

In a previous study, the growth of the species was estimated from a model simpler than those developed below and from another set of otoliths. These otoliths came from fish sampled on board commercial trawler in 1996-97 (Allain and Lorance, 2000). In order to improve the estimated growth parameters and to compare the results obtained from two sets of otoliths read by two different readers, the length at age data from Allain and Lorance (2000) was re-used. The growth parameters will be given here for two data sets. The sample read for this study, from fish collected during scientific cruises in 1996 and 1999 will be referred to below as 1999 data set, the other from fish collected on commercial trawlers in 1996-97, already dealt with by Allain and Lorance (2000) as 1997 data set. These two data sets are completely independent, and otolith weights (see below) were available only for the 1999 data set.

The otolith readings were carried out in late 2000 and 2001 (i.e. after a sufficient time for the otolith drying in the ambient conditions of the laboratory). One otolith from each of 953 individuals was read. The weight of one otolith from 698 individuals was estimated from the half weight of the pair of otoliths weighed to the nearest $0.1 \mathrm{mg}$, except in a few cases where only one single otolith in good condition was available.

\section{Preparation and reading of otoliths}

Two reading methods were applied to two sets of otoliths. A large set of 848 otoliths from fish measuring 1.5 to $25 \mathrm{~cm}$ PAFL was embedded in translucent polyester resin, cut in thin slices on a BUELHER ISOMET low speed diamond saw in their dorso-ventral axis. The slices were made as thin as possible, but the slices of the larger otoliths became very fragile and difficult to handle without damage when they were cut too thin. Two or three slices per otolith were cut. The thickness of a set of 30 slices was measured on a MITUTOYO comparator. The thin slices were read under transmitted light on a LEITZ LABOVERT inverted microscope fitted with a black and white video camera connected to a SONY TRINITRON 21" monitor. The counting of the otoliths annuli was mainly done on the monitor screen. However, direct vision through the microscope oculars was used to clearly identify the thinner annuli using magnifications up to $125 \mathrm{x}$.

Another set of 105 otoliths from fish measuring 2 to $6 \mathrm{~cm}$ PAFL were read as whole otoliths under reflected light on a LEICA MZ6 binocular microscope fitted to the same video camera and monitor as above. The magnification used on the microscope was $8 \mathrm{x}$ to $16 \mathrm{x}$ when the image was read on the Sony Monitor and up to $40 \mathrm{x}$ when reading in the microscope oculars.

The interpretation scheme of the whole otoliths was quite straightforward as they displayed very clear rings that could be followed around almost the entire otolith (Fig. 1a). These rings correspond to the hyaline zones seen on the thin slices and similar to the growth zones of gadoid species as described by Bergstad (1990) (Fig. 1b). For fish above about $6 \mathrm{~cm}$ PAFL, whole otoliths were difficult to read due to their increasing thickness, so all the larger individuals were read in thin slices. The readings of the thin slices were carried out as described by Kelly et al. (1997). Usually, 6 to 8 rings were counted in the dorso-ventral axis (Fig. 1b, 2) and correspond to the pre-collar growth of Kelly et al., (1997) and the further zones were counted in the post-collar growth zone (Fig. 2; see also Fig. 5 in Kelly et al., 1997).

\section{Fitting of the Von Bertalanffy growth model}

The Von Bertalanffy growth model was used to estimate the growth of the species and to compare the growth of males and females. As usual, the model expresses as:

$$
L_{t}=L_{\infty}\left(1-e^{-k\left(t-t_{0}\right)}\right)
$$

where: $L_{t} \quad$ is the size at time $t$

$L_{\infty}$ is the asymptotic length of the species

$k \quad$ is the growth coefficient

$t_{0}$ is a parameter which has variable interpretations among authors, some considering it a mathematical artefact and others allocating it an actual biological time (the theoretical time at which the fish would have a length of $0)$. 


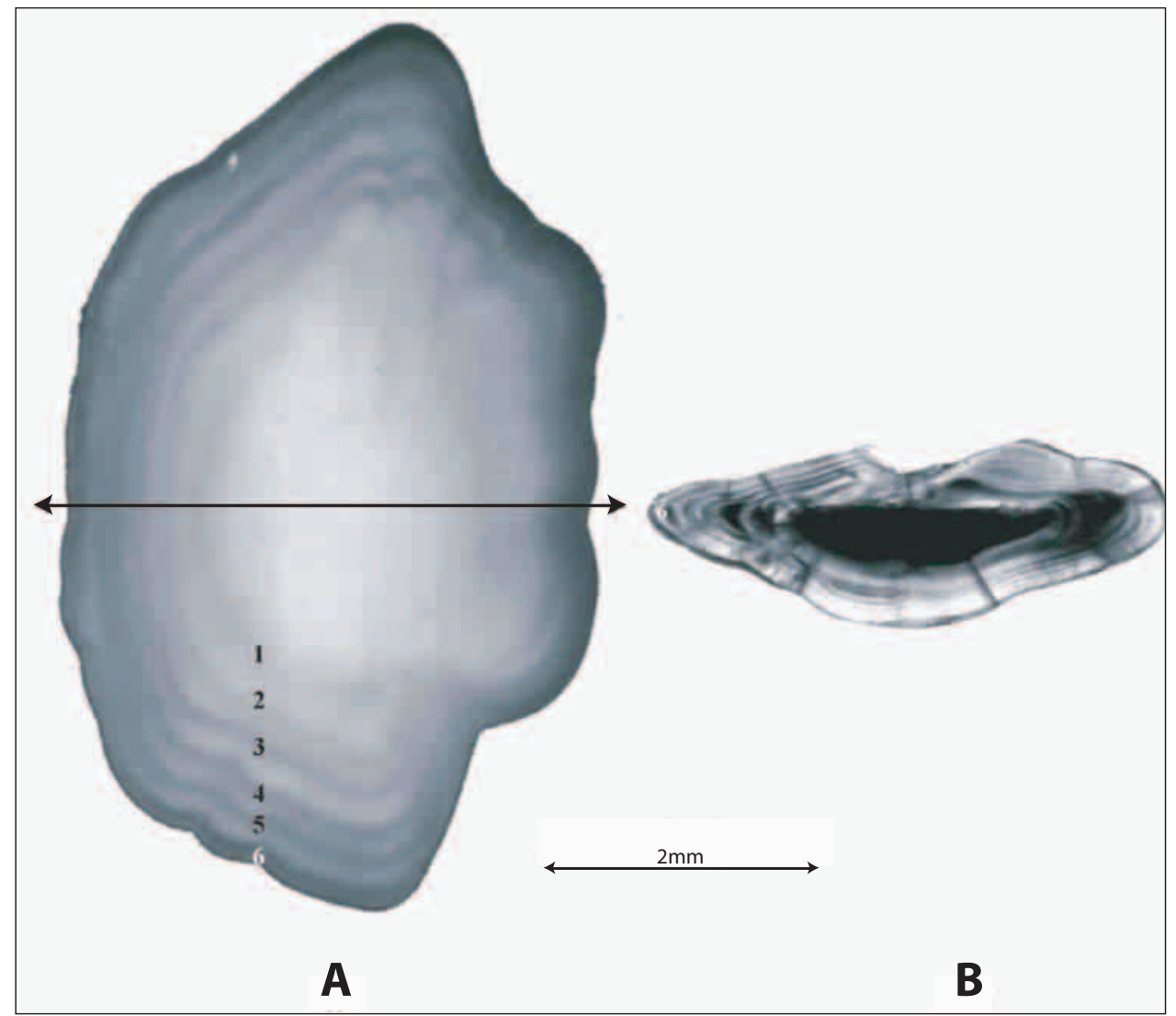

Fig. 1. Correspondence of (A) annuli read on the outer face of a whole sagittal otolith seen under reflected light and (B) those on the dorso-ventral axis of a transverse section of the same otolith under transmitted light. The cutting axis is represented on the whole otolith.

Two adjustment methods were used for the Von Bertalanffy model:

1. Based on the hypothesis of normality of residuals, Kimura (1980) proposed to calculate the parameters from a likehood function of the normal distribution function associated to the residuals. Under the hypothesis of constant variance the function to minimize is:

$\sum\left(L_{t i}-L_{\infty}\left(1-\exp \left(-k\left(t_{i}-t_{0}\right)\right)\right)\right)^{2} i=1, \ldots . n($ Model 1)

where: $L_{\infty}, k$ and $t_{0}$ are the parameters to estimate;

$L_{t i}$ is the length of the $i$ th individual of age $t_{i}$.

2. In the case where the variance of $L_{t i}$ varies with $t_{i}$, Kimura (1980) proposed a weighted model where the function to minimize is:

$$
\sum \frac{n t}{\widehat{\sigma} t_{2}}\left(\bar{L}-L_{\infty}\left(1-\exp \left(-k\left(t_{i}-t_{o}\right)\right)\right)\right)^{2}
$$

In order to do this fit, the observed length of each individual was transformed to:

$$
y_{t i}=\frac{1}{\widehat{\sigma}_{t}} L_{t i}(i=1, \ldots n)
$$

and the parameters were estimated from a regression on $y$ :

$$
y=\left(\frac{1}{\hat{\sigma} t}\right)\left[L_{\infty}\left(1-\exp \left(-k\left(t-t_{0}\right)\right)\right)\right]
$$

The estimation of the growth parameters for males and females and the significance of the difference between the two sexes were estimated from the weighted model (model 2). The differences in $k$ and $L_{\infty}$ between sexes were introduced as extra parameters in the model. It was decided not to include a parameter for the deviation in $t_{0}$. Considering $t_{0}$ as the hypothetical age at length 0 (Kimura, 1980), there is no biological reason that it would be different between males and females. If it is a model parameter without biological meaning (Pauly, 1997), there is no more 


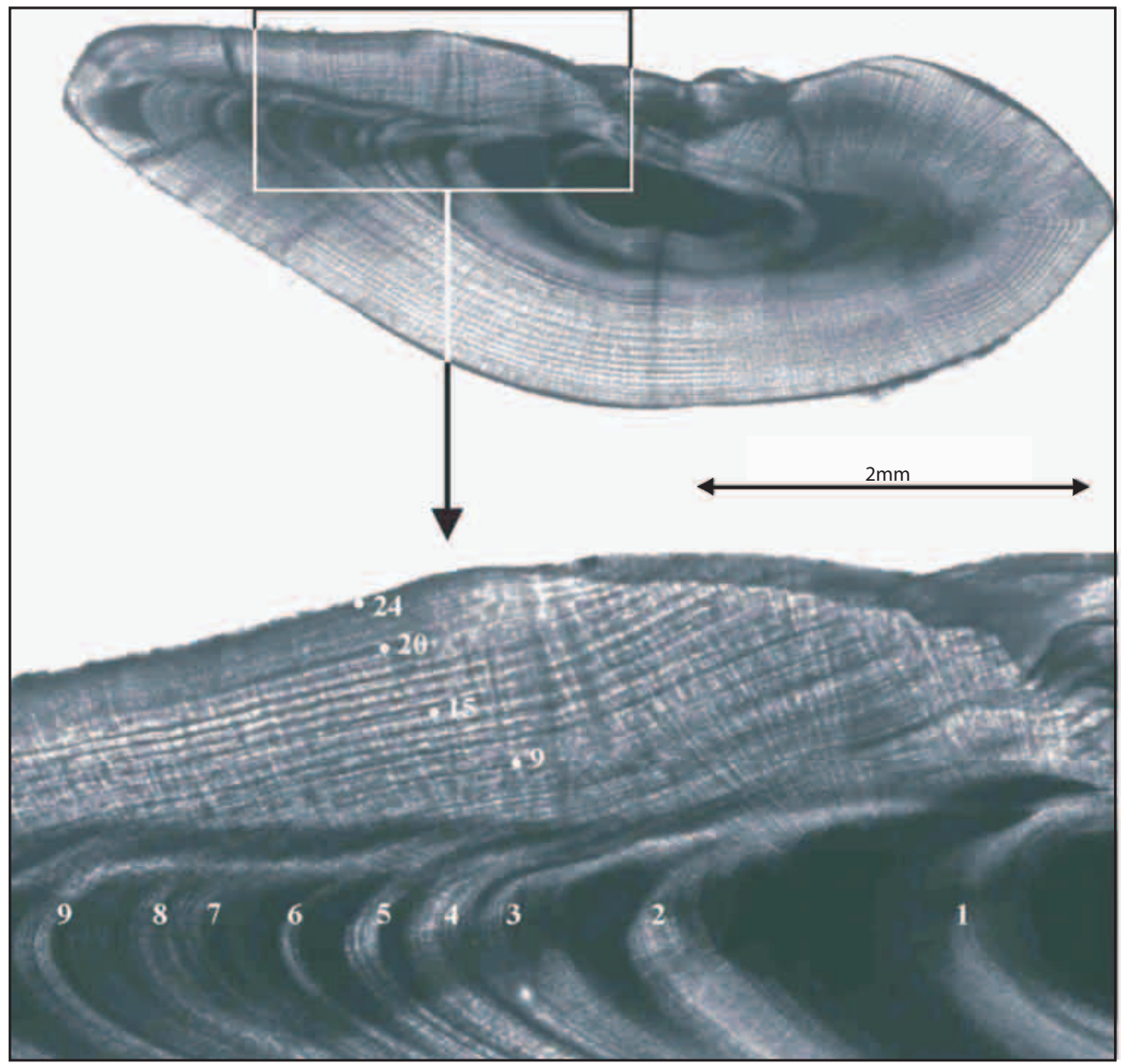

Fig. 2. Reading axis of a transversal section of an otolith seen under transmitted light.

reason to make it different between males and females. Lastly, a unique $t_{0}$ keeps the analysis simpler.

In other words, indexing the parameters of males and females by $m$ and $f$, the model to adjust is:

$$
y=\left(\frac{1}{\hat{\sigma}_{t}}\right)\left[\left(L_{\infty m}+\Delta L_{\infty}\right)\left(1-\exp \left(-\left(k_{m}+\Delta k\right)\left(t-t_{0}\right)\right)\right)\right]
$$

(Model 3)

where $\Delta L_{\infty}$ and $\Delta k$ are the differences in $L_{\infty}$ and $k$ between females and males. These differences were arbitrarily set as $L_{\infty f}-L_{\infty m}$ and $k_{f}-k_{m}$.

To assess these parameters, the Gauss-Newton iteration algorithm was used with S-Plus software (Anon., 1999). Kimura (1980) used the maximum likelihood method to have the best properties of the estimation: consistency, smallest possible variance and asymptotic normality. Antoniadis et al. (1992) showed that when the errors are normally distributed, the model is non-linear Gaussian and under those conditions the maximum likelihood estimators and the mean square estimators are the same.

From the 1997 data set, (Allain and Lorance, 2000) estimated the growth of the species using model 1. The $\Delta L_{\infty}$ and $\Delta k$ and a similar $\Delta t_{0}$ parameters were included in the model 1. The difference between sexes was tested from Student's t-test of these three parameters. More precisely, a nested system was used to test, first, the significance of the three parameters, then that of $\Delta L_{\infty}$ and $\Delta k$ together, when no significant difference in $t_{0}$ was assumed and finally that of $\Delta L_{\infty}$ alone or $\Delta k$ alone when no significant differences in $t_{0}$ and, $k$ or $L$, respectively were assumed. In this nested system, the parameters were tested independently, irrespective of their colinearity. It was concluded from that study that only the parameter $L_{\infty}$ was different between males and females (Allain and Lorance, 2000). 


\section{Construction of confidence bounds and confidence region}

The confidence bounds of each parameter are calculated with the "profile" function of S+ software. This method for a given parameter, $\theta_{p}$, uses a function that is equivalent to the studentized parameter $\delta\left(\theta_{p}\right)$ (Anon., 1999):

$$
\delta\left(\theta_{p}\right)=\frac{\theta_{p}-\hat{\theta}_{p}}{\sigma\left(\hat{\theta}_{p}\right)}
$$

where $\hat{\theta}_{p}$ is the model estimate of $\theta_{p}$.

Then a confidence interval can be constructed as follows:

$$
-t_{(N-p, \alpha / 2)} \leq \delta\left(\theta_{p}\right) \leq t_{(N-p, \alpha / 2)}
$$

The comparison between the two sets of growth parameters for males and females was carried out by constructing the confidence region of the pair of parameters $\theta=\left[\begin{array}{c}L_{\infty} \\ K\end{array}\right]$ for each set. The confidence region for a vector of estimated parameters $\hat{\theta}$ is defined as the $\theta$, values such as (Rooney and Biegler, 1999):

$$
(\theta-\hat{\theta})^{\prime} X^{\prime} X(\theta-\hat{\theta}) \leq \hat{\sigma}^{2} p F_{p, n-p}^{-1}(1-\alpha)
$$

Due to the correlations between the parameters in $\theta$, these areas have an ellipsoidal shape.

\section{Fitting of the age - otolith weight relation}

A linear regression was used to fit the relation between the age of the individual and its otolith weight. In order to investigate the differences between male, female and immature, a covariance analysis was carried out.

The model can be written as:

$$
y_{i s}=\left(a+\alpha_{s}\right)+\left(b+\beta_{s}\right) x_{i s}+\varepsilon_{i s}
$$

where $y_{i s}$ and $x_{i s}$ are the age and the otolith weight of the individual $i$ and $\operatorname{sex} s$, $\alpha_{s}, \beta_{s}$ are the additive sex effect on the intercept and the slope of the regression,

and $\quad \varepsilon_{i s}$ is the error between the measure and the prediction.

F tests were used to quantify the probability of a sex effect on the relation between age and otolith weight.

\section{Results}

\section{Ranges of size, age and otolith weight in the sample (1999 data set)}

Age estimates were attributed to all of the 105 otoliths read in whole. These ages ranged from 2 to 8 years. The average thickness of the thin slices was $0.24 \mathrm{~mm}$. Of the 848 otoliths read in thin slices, 30 were judged unreadable. The 818 readable otoliths in thin section and 105 whole otoliths means that a total of 923 age estimates were available (444 for males, 289 for females, 190 for immatures/unsexed). The global range of ages was 2 to 45 years. In constructing an age-length key, 4 individuals appeared to be outliers as very old relative to their size. The otoliths of these individual had also inconsistent otolith weights relative to the size of the fish and were excluded from further analysis. Such discrepancies were believed to result from writing errors of the fish lengths (misunderstanding of tens numbers during on board sampling).

The otolith weight ranged from $13 \mathrm{mg}$ in 2 immature individuals measuring $2 \mathrm{~cm}$ PAFL to 865 $\mathrm{mg}$ in one large female measuring $24 \mathrm{~cm}$ PAFL.

\section{VBGM}

The residuals from the model 1 were normally distributed (Fig. 3A). However, there was a clear trend of increasing residuals with age (Fig. 3C). In other words, the variance increases with $t_{i}$. This trend in the residuals disappeared with model 2 (Fig. 3D) while the global normal distribution of the residuals was kept (Fig. 3B). Then, the parameters were further estimated from the model 2 . It can be noted, however, that the growth curves obtained from the two models diverge only for the older ages (Fig. 4) and the estimates of $L_{\infty}$ and $k$ have large overlapping confidence intervals (Table 1).

Like for model 2, the residuals from the model 3 were normally distributed without trend with age. The parameters for the difference between females and males are significant, the model indicates that females grow more slowly ( $\Delta k$ is negative) but reach a larger size ( $\Delta L_{\infty}$ is positive).

The estimated parameters from the data set for 1997 were different (Table 2). For both males and females $L_{\infty}$ was lower and $k$ was higher in the 1997 data set. For males, the confidence intervals from the two data sets overlapped strongly while for females 

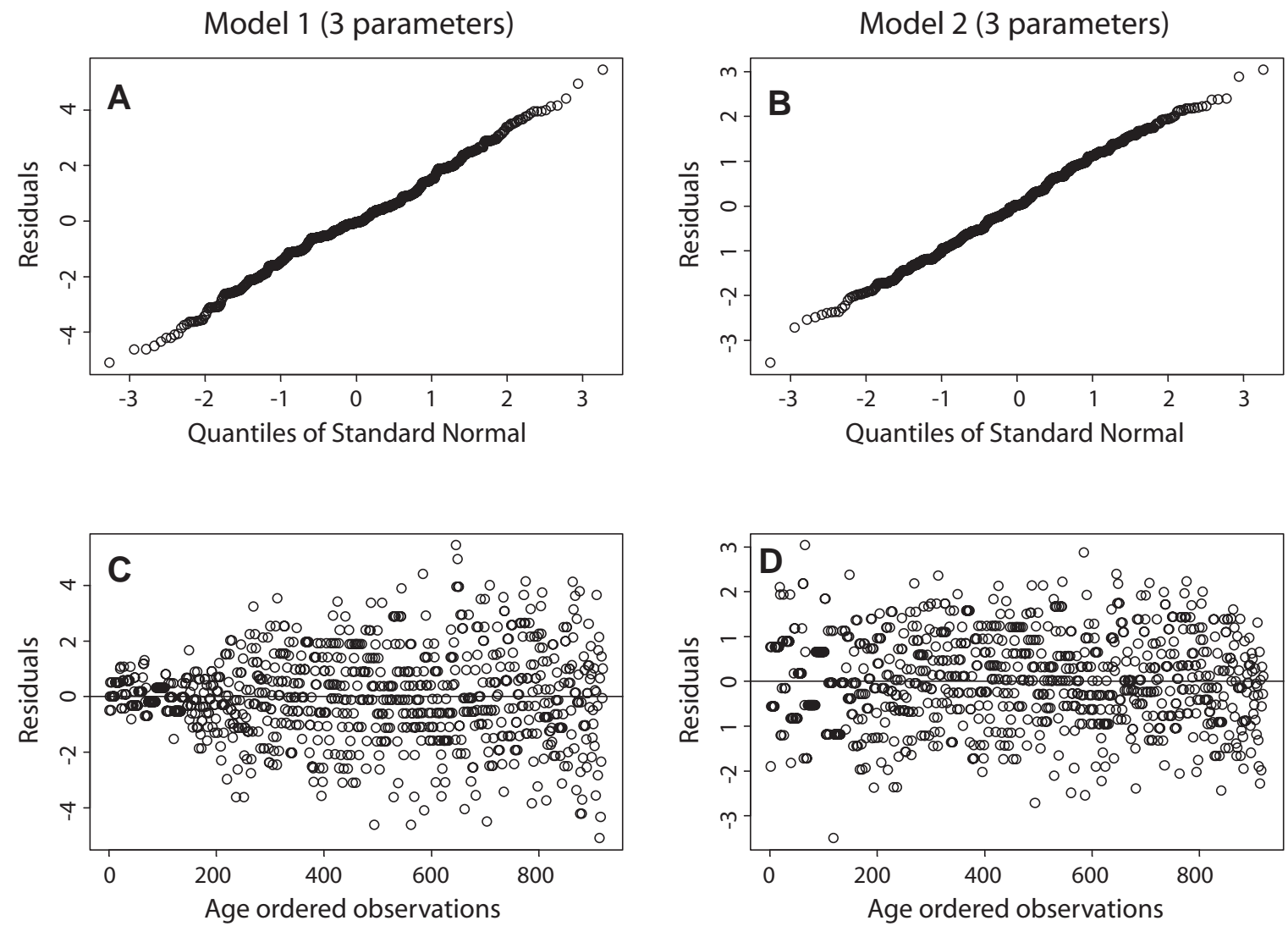

Fig. 3. Residuals of the models 1 and $2 v s$ the quantiles of the normal distribution (A and $\mathbf{B})$ and distribution of the residuals according to the estimated age ( $\mathbf{C}$ and $\mathbf{D})$.

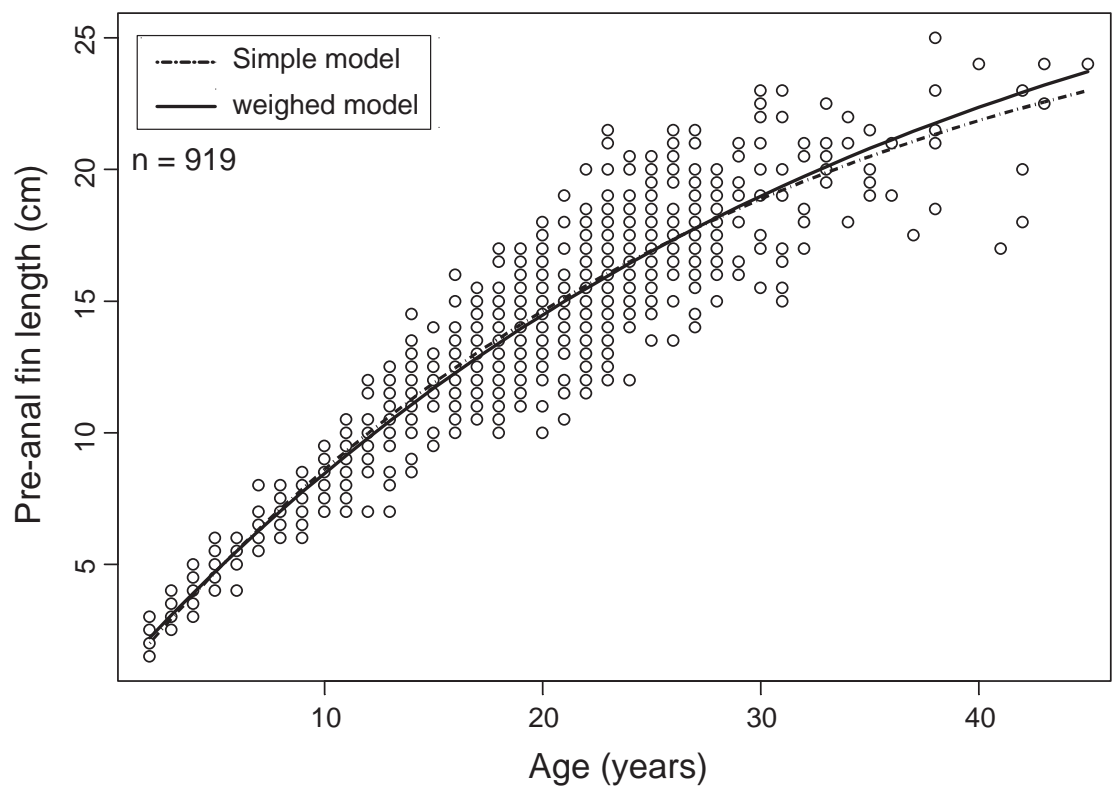

Fig. 4. Fitting of the simple model (Model 1) and the weighted model (Model 2) to all the age estimates. 
TABLE 1. Von Bertalanffy growth model: parameters and their $95 \%$ confidence intervals for models 1,2 and 3 (see text), $L_{\infty}$, and $k$ were set as the parameters for males and $\Delta L_{\infty}$, and $\Delta k$ as the difference between females and males (see text).

\begin{tabular}{cccccc}
\hline \hline Model & $L_{\infty}(\mathrm{cm})$ & $\Delta L_{\infty}(\mathrm{cm})$ & $k\left(\mathrm{yr}^{-1}\right)$ & $\Delta k\left(y r^{-1}\right)$ & $t_{0}(\mathrm{yr})$ \\
\hline 1 & $28.9(27.0-31.3)$ & & $0.035(0.031-0.040)$ & & $-0.03(-0.5-0.4)$ \\
2 & $32.4(29.3-36.7)$ & & $0.029(0.024-0.034)$ & & $-0.4(-0.7-0.2)$ \\
3 & $24.9(23.1-27.2)$ & $6.9(3.2-11.2)$ & $0.042(0.037-0.047)$ & $-0.011(-0.018--0.0039)$ & $-0.4(-0.7-0.2)$ \\
\hline
\end{tabular}

TABLE 2. Comparison of estimated growth parameters from model 3 (see text) for males and females from the 1997 and 1999 data sets. The model assumes no difference in $t_{0}$.

\begin{tabular}{lccccc}
\hline \hline & \multicolumn{3}{c}{ Males } & \multicolumn{1}{c}{ Females } \\
Sample & $L_{\infty}(\mathrm{cm})$ & $k\left(\mathrm{yr}^{-1}\right)$ & $L_{\infty}(\mathrm{cm})$ & $k\left(\mathrm{yr}^{-1}\right)$ & $t_{0}(\mathrm{yr})$ \\
\hline 1997 & $23.2(21.8-24.7)$ & $0.044(0.039-0.045)$ & $28.2(27.0-29.7)$ & $0.038(0.03-0.042)$ & $-2.2(-3.2-1.4)$ \\
1999 & $24.9(23.1-27.2)$ & $0.042(0.037-0.047)$ & $31.9(28.8-35.9)$ & $0.031(0.026-0.036)$ & $-0.4(-0.7-0.2)$ \\
\hline
\end{tabular}

the overlaps was less important but for both parameters the confidence intervals indicate that the differences between the two data sets are not significant. Considering the confidence areas of the parameters, the difference between males and females clearly appears and the results from the 1997 and 1999 samples are significantly different (Fig. 5). The difference is larger for females than for males, for which the estimated $L_{\infty}$ is lower and $k$ higher for the 1997 data set.

\section{Relationship between otolith weight and fish length and age}

The weight of otoliths increased with the fish length and the estimated age. Expectedly, as a relationship between a weight estimate and a length estimate, the scatter plot of otolith weight $v s$ PAFL showed a curvilinear relation (Fig. 6). The global linear regression between the estimated ages and the otolith weights appeared to have a clear structure in the residuals. This structure disappeared in the model including a sex effect and the covariance analysis showed that the slopes were significantly different $(p<0.01)$ for the 3 categories, the intercept for males and females was not significantly different but was different from that of juveniles (Table 3). As some outliers (such as a large unsexed individual) were included in the computation, the relationships were recomputed over more restricted ranges of otolith weights with minor reduction in the number of individuals included in the regressions (Table 4). The coefficients were only slightly different and the covariance analysis results were the same. However the variance of age increased with otolith weight, the age of a fish can be predicted from its otolith weight (Fig. 7). However, the variance is pretty large, a 210 $\mathrm{mg}$ otolith varies between 12-27 years age and a 600 $\mathrm{mg}$ otolith could be between about 20 to 40 years age.

\section{Discussion}

\section{Comparing VBGM parameters}

Comparison of growth based upon the parameters $L_{\infty}$ and $k$ of the VBGM can be fallacious (Pauly, 1997). This is due to the strong colinearity between the two parameters and also to the available samples. It is likely that the higher $L_{\infty}$ obtained here from the 1999 data set comes from a lower proportion of large individuals than in the 1997 data set. This effect was much stronger for females, probably because with increasing size, a larger proportion of individuals are females. In the 1997 sample the larger individuals force the model fit towards the plateau of the observed PAFL/age scatter plot. This is indeed a property of any regression fit that predicted values out the range of the observed value are very poor. Estimating $L_{\infty}$ from a VBGM amounts to estimating a predicted value at the right end of the scatter plot of observed value. This cannot be done accurately unless the sample contains a sufficient number of large individuals, in which growth has levelled off. Although accurate 


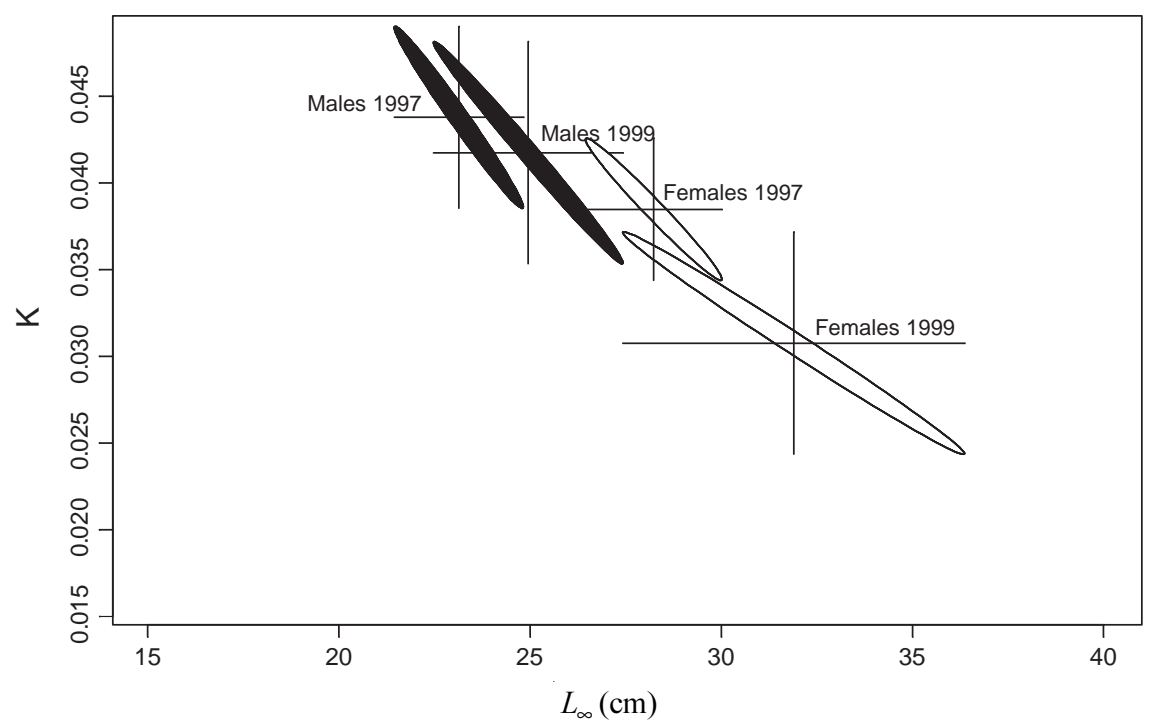

Fig. 5. Confidence areas of the couples of growth parameters $k$ and $L_{\infty}$ for males and females from the two data sets.

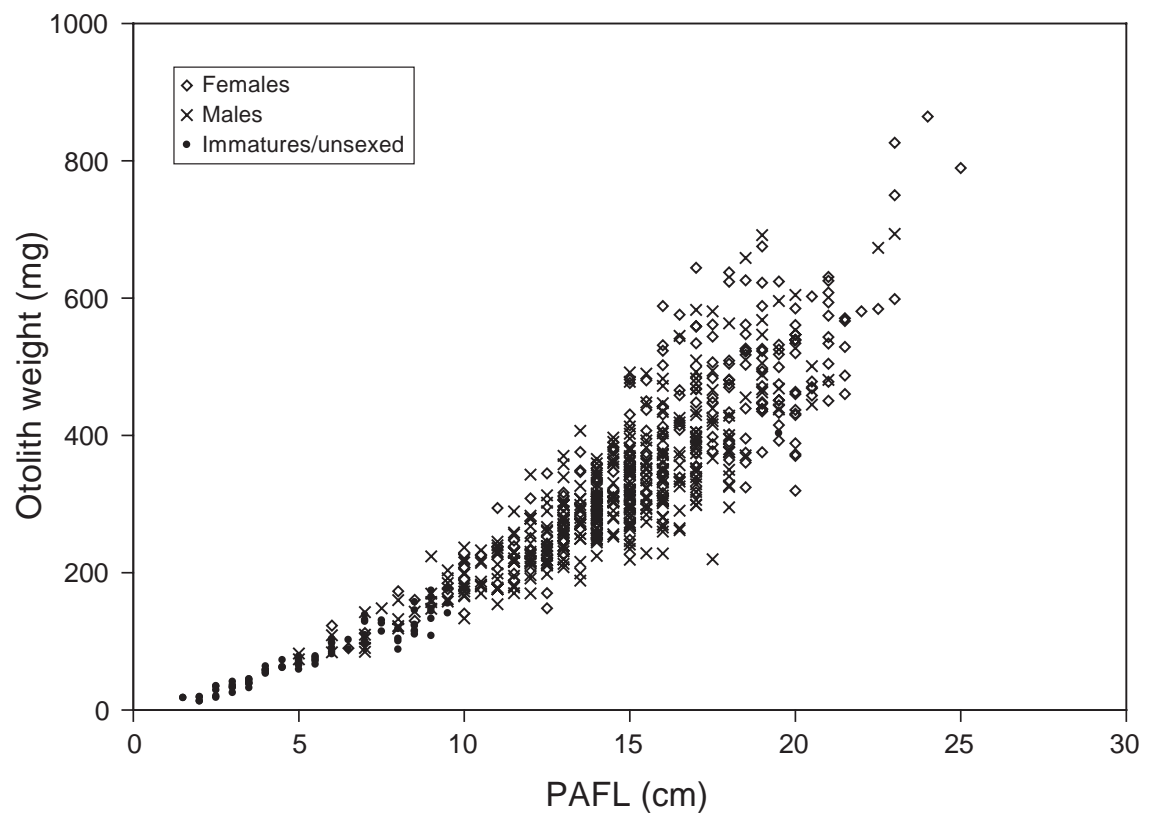

Fig. 6. Distribution of otolith weights relative to fish length.

modelling, such as the weighted models 2 and 3, can improve the estimated parameters, a lack of large individuals cannot be balanced. So, growth parameters estimated from an exploited population may be misleading, in particular in the case of a long lived and slow growing species such as the roundnose grenadier. On the other hand, the sizes predicted by the model 3 for the oldest female ( 45 years) and male (42 years) are respectively 24 and $20.5 \mathrm{~cm}$ PAFL in agreement with observed values. Expectedly, predicted sizes are consistent as long as they are in the range of observed values.

The absence of large individuals may result from the effect of the fishery, from the sampling depth or a combination of both. The effect of the fishery is reflected in the time series of the length distribution of the French landings where the proportion of larger 
TABLE 3. Parameters, determination coefficient, numbers of individuals and ranges (in otolith weight and fish size) of the regressions of age $v s$ otolith weight, for the complete data set.

\begin{tabular}{lcccccc}
\hline \hline & & & & & \multicolumn{2}{c}{ Ranges } \\
\cline { 5 - 6 } & Slope & Intercept & $\mathrm{R}^{2}$ & $\mathrm{~N}$ & Otolith weight (mg) & PAFL (cm) \\
\hline Males & 0.047 & 5.61 & 0.75 & 392 & $74-694$ & $5-23$ \\
Females & 0.040 & 7.08 & 0.72 & 205 & $90-865$ & $6-25$ \\
Immature/Unsexed & 0.067 & 1.05 & 0.94 & 83 & $13-403$ & $1.5-19.5$ \\
\hline
\end{tabular}

TABLE 4. Parameters, determination coefficient, numbers of individuals and ranges (in otolith weight and fish size) of the regressions of age $v s$ otolith weight, for the restricted ranges of otolith weights.

\begin{tabular}{|c|c|c|c|c|c|c|}
\hline & \multirow[b]{2}{*}{ Slope } & \multirow[b]{2}{*}{ Intercept } & \multirow[b]{2}{*}{$\mathrm{R}^{2}$} & \multirow[b]{2}{*}{$\mathrm{N}$} & \multicolumn{2}{|c|}{ Ranges } \\
\hline & & & & & Otolith weight (mg) & $\operatorname{PAFL}(\mathrm{cm})$ \\
\hline Males & 0.045 & 6.30 & 0.70 & 380 & $140-694$ & $7-23$ \\
\hline Females & 0.039 & 7.75 & 0.69 & 201 & $140-865$ & $8-25$ \\
\hline Immature/Unsexed & 0.073 & 0.61 & 0.88 & 81 & $13-175$ & $1.5-9.5$ \\
\hline
\end{tabular}

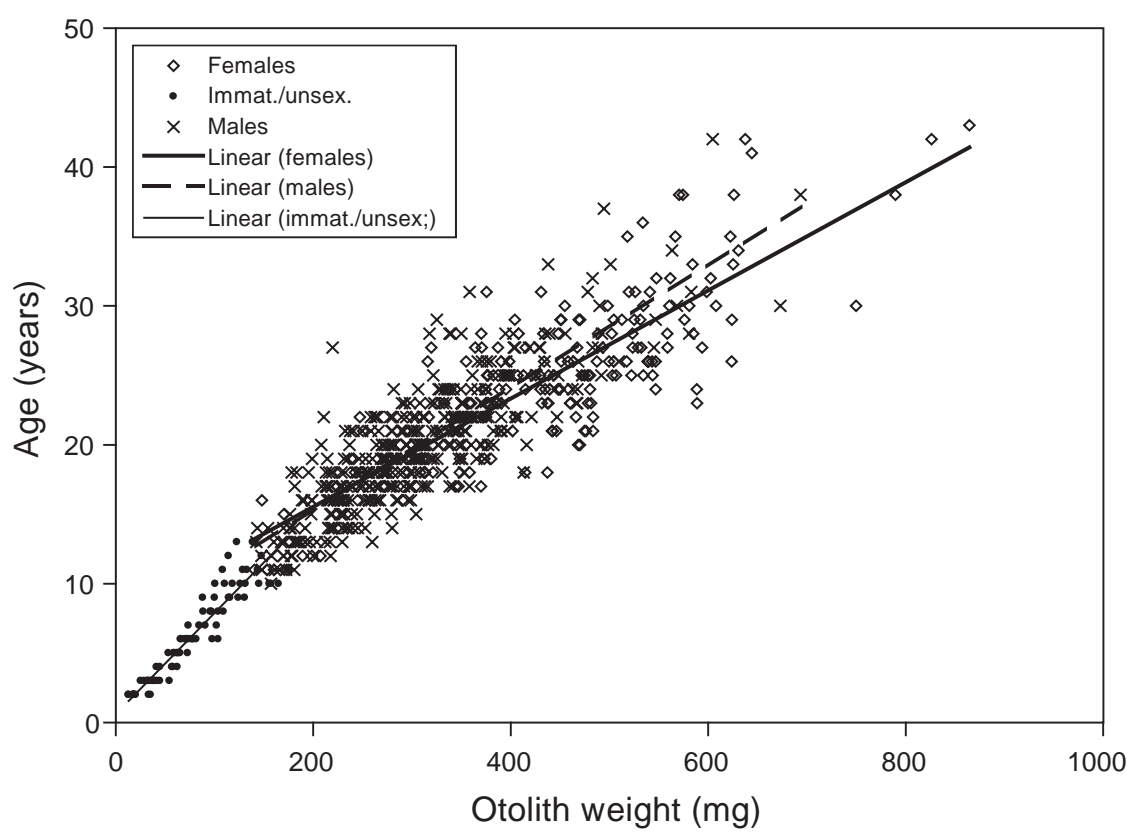

Fig. 7. Distribution of estimated ages relative to otolith weight and linear regression for male, female and immature fish.

individuals decreased over time (Anon., MS 2000). In terms of depth of sampling, off the west coast of Scotland, C. rupetris has a complex size distribution by depth and sex (Gordon, 1979; Mauchline and Gordon, 1984). Large fish are found in the shallow part of the depth distribution of the species. Deeper, a bimodal size distribution, with both juvenile and adult fish is observed at about 1000-1 $300 \mathrm{~m}$. Lastly fish of intermediate size are found deeper (see Fig. 4 in Gordon, 1979). According to this, the depth range sampled during our 1999 cruise was not the most favourable for catching large individuals. It may be 
also that the size reached by the roundnose grenadier does not clearly level off before the natural death of most individuals in the study area. However, this is very hypothetical and does not occur in the Skagerrak, where Bergstad (1990) did observe a very clear and long plateau in the length at ages, but in this area the species reaches smaller sizes.

Lastly, the confidence areas allow us to compare the growth parameters of males and females much more accurately than the nested model formerly used (Allain and Lorance, 2000), which does not account for the colinearity between the parameters.

\section{Effects of uncertainties on ages}

Due to these problems with estimation of the growth parameters, several authors have proposed methods to compare the growth performance of populations. Zivkov et al. (1999) listed 19 indices and parameters found in the literature for comparing fish growth rates. They concluded that the most accurate was to compare length increments at ages. Such comparison may be of interest for deep-water species to test for differences between geographical areas and over time. The first case would shed light on stock identity, the second on the possible reaction of the populations to depleted fish density due to the fishery (Anon., MS 2000; Lorance and Dupouy, 2001). The length increment method proposed by Zivkov et al. (1999) was tried here. However, in our case we only have one length at age per fish while Zivkov et al. (1999) used back calculation to estimate the length at several age of each fish (they estimated the average growth increment of age groups 1-10). Using the mean length at ages for roundnose grenadier leads to negative average length increments for some age groups due to both the slow growth of the species and the wide variance of individual length at age. The back-calculation is difficult to apply to this species beyond the few first years (pre-collar growth) due to the narrowness of the growth increments on the otoliths and to the use of two different reading axes (Fig. 2).

Although more accurate growth analysis such as that proposed by Zivkov et al. (1999) does not seem to apply, our estimates of growth parameters cannot be considered as very reliable, due to the lack of large individuals. The problem is probably more serious the for the index of size $\left(L_{\infty}\right)$ than for that of growth $(k)$ according to Francis' (1996) definition. In terms of stock assessment, age-length keys can probably be used, although the age estimated from the fish of commercial size are still not fully validated. On the other hand, comparison of growth between different areas or over time would require a sufficient sampling of large individuals which may be difficult to obtain when the respective populations have been exploited for long.

It is likely that the large variance of individual length at age comes from a combination of the individual variability in growth and age reading errors. These also apply to the relationship between age and otolith weight. The use of the $L_{\infty}$ and $k$ parameters should proceed with caution. However, since the $k$ parameter appeared here as less sensitive to sampling problems, its use in the Beddington and Cooke procedure (Beddington and Cooke, 1983) may still be of help for future assessment of the stocks.

Notwithstanding the reservations given here, the roundnose grenadier is believed to be one species for which age-based assessment may soon become possible (Large et al., 2003; Lorance et al., 2001). In this perspective, the possibility to estimate the age composition of the population from the weight distribution of the otoliths in the catch seems attractive. To our knowledge this has seldom been used. In the case of the deep-water species, it may be of serious help due to the cost (in term of staff time) of optical age reading. Moreover, it should be considered that measuring the length of this species might not be a very reliable process. The use of the PAFL allows more accurate sampling of this species than the total length due to the frequently damaged tail of the species during the catch and the practice of cutting it off in commercially landed fish. However, when stored in ice, the roundnose grenadier looses water, in particular in its head and snout parts. Indeed, the measurement of PAFL in eviscerated individuals from commercial landing may be unreliable due to variable time spent in ice and evisceration methods. These may change from year to year and are clearly different between commercially landed fish (iced and eviscerated) and the freshly caught fish sampled during surveys. A direct sampling of ages, by otolith weight, may allow skipping these sources of bias. Moreover, it would allow estimating the ages of a much larger sample of individuals and could indeed improve the accuracy of the age composition estimated for the population or the landings. However, in order to validate the use of otoliths weights as a proxy for ages, the age distribution derived from otolith readings and from the age $v s$ otolith weights relationship is required. This cannot be done from one single sample because then age distributions are not stochastically independent. A further work is now to test this 
hypothesis by building an age length key from optical reading on a sample taken from the fishery and comparing the derived age composition to that estimated from the age $v s$ otolith weights relationship calculated here.

\section{Further perspectives}

Deep-water species provide opportunities to investigate how fish populations react to fishery exploitation, because some data prior to exploitation are available. However, such data are sparse even to the West of Scotland, a comparatively very well sampled area. Although limited, this opportunity should not be disregarded, as it is quite unique in fishery-exploited species. In term of growth, change over time due to depleted density may occur. The VBGM is probably not a good candidate to study this point as large individuals would be more depleted by the fishery and the accuracy of the parameters would decline with increasing depletion. However, the present study shows that improved modelling (here the use of the weighted model) increases the accuracy of the estimated growth parameters. A potential flaw in the analysis is the lack of older larger individuals due to the effects of the fishery, this may require the high sampling effort for exploited populations. The present study clearly suffered from this lack of larger individuals.

Alternative methods need to be investigated and may lie with back-calculation (Jones, 2000; Zivkov et al., 1999). The method from Zivkov and colleagues was used here on the mean length at age with poor success. Back-calculated length at ages would be more efficient, but their application to the reading scheme for roundnose grenadier is not straightforward.

Attractive too is the use of the regression of age vs otolith weight, which may allow avoiding some sampling problems. This approach needs further studies, but the present work provides estimated parameters that can be applied to further samples to compare the age-length keys from optical reading and age-otolith weight regression. To this end, sampling and age estimation of landed fish are in progress.

\section{Acknowledgements}

Thanks are due to J. A. Moore and one anonymous referee for useful comments on a former version of this study. Dr. F. Uiblein (University of Salzburg) kindly read the manuscript and provided additional remarks. We acknowledge our colleagues from
IFREMER and other research institutes for their participation in the cruises during which the fish were sampled and S. Gros (IFREMER, Brest) for her assistance with the figures.

\section{References}

ALLAIN, V. 1999. Ecologie, biologie et exploitation des populations de poissons profonds de l'Atlantique du nordest. Océanologie Biologique, Université de Bretagne Occidentale, Brest, France, 376 p.

2001. Reproductive strategies of three deep-water benthopelagic fishes from the northeast Atlantic Ocean. Fish. Res., 51(2-3): 165-176.

ALLAIN V., and P. LORANCE. 2000. Age estimation and growth of some deep-sea fish from the Northeast Atlantic ocean. Cybium, 24(3 suppl.): 7-16.

ANDREWS, A. H., G. M. CAILLIET, and K. H. COALE. 1999. Age and growth of the Pacific grenadier (Coryphaenoides acrolepis) with age estimate validation using an improved radiometric ageing technique. Can J. Fish. Aquat. Sci., 56(8): 1339-1350.

ANNALA, J. H., K. J. SULLIVAN, C. J. O'BRIEN, N. W. M. SMITH, and S. J. A. C. VARIAN. MS 2002. Report from the Fishery Assessment Plenary, May 2002: stock assessments and yield estimates. Unpublished report held in NIWA library, Wellington, $640 \mathrm{p}$.

ANON. MS 1998. Report of the study group on the biology and assessment of deep-sea fisheries resources. ICES C.M. Doc., No. ACFM:12, 172 p.

MS 1999. S-PLUS 2000, Guide to statistics, volume I. Seattle, Washington, USA, $638 \mathrm{p}$.

MS 2000. Report of the study group on the biology and assessment of deep-sea fisheries resources. ICES C.M. Doc., No. ACFM:8, 205 p.

ANTONIADIS, A., J. BERRUYER, and R. CARAMONA. 1992. Régression non linéaire. Coll. "Economie et statistiques avancées". Economica, Paris, France, 275 p.

ATKINSON, D. B. 1995. The biology and fishery of roundnose grenadier (Coryphaenoides rupestris Gunnerus, 1765) in the north west Atlantic. In: Deepwater fisheries of the north Atlantic oceanic slope. A. G. Hopper (ed.). Series E: Applied Sciences. Kluwer Academic Publishers, Dordrecht/Boston/London, p. 51-111.

BEAMISH, R. J., and G. A. MCFARLANE. 1983. The forgotten requirement for age validation in fisheries biology. Trans. Amer. Fish. Soc., 112(6): 735-743.

BEDDINGTON, J. R., and J. G. COOKE. 1983. The potential yield of fish stocks. FAO Fish. Tech. Pap., 242: 47 p.

BERGSTAD, O. A. 1990. Distribution, population structure, growth and reproduction of the roundnose grenadier Coryphaenoides rupestris (Pisces: Macrouridae) in the deep waters of the Skagerrak. Mar. Biol., 107: 25-39.

BRIDGER, J. P. MS 1978. New deep-water trawling grounds to the West of Britain. Lab. Leaf., MAFF Direct., Lowestoft, No. 41, 40 p.

CHARUAU, A., H. DUPOUY, and P. LORANCE. 1995. French exploitation of the deep-water fisheries of the 
North Atlantic. In: Deep-water fisheries of the North Atlantic oceanic slope. A. G. Hopper (ed.). Series E: Applied Sciences. Kluwer Academic Publishers, Dordrecht/Boston/London, p. 337-356.

CLARK, M. 2001. Are deepwater fisheries sustainable? the example of orange roughy (Hoplostethus atlanticus) in New Zealand. Fish. Res., 51(2-3): 123-135.

CLARK, M. R., O. F. ANDERSON, R. I. C. C. FRANCIS, and D. M. TRACEY. 2000. The effects of commercial exploitation on orange roughy (Hoplosthetus atlanticus) from the continental slope of the Chatham Rise, New Zealand, from 1979 to 1997. Fish. Res., 45: 217-238.

DURÁN MUÑOZ, P., and E. ROMÁN. MS 2001. The Spanish Multi-species Deep-sea Fishery at Hatton Bank (Northeast Atlantic): 1996-2000, NAFO SCR Doc., No.120, Serial No. N4508, 20 p.

EHRICH, S. 1983. On the occurrence of some fish species at the slopes of the Rockall Trough. Archiv fur Fischereiwissenschaft, 33(3): 105-150.

FRANCIS R. I. C. C., 1996. Do herring grow faster than orange roughy? Fish. Bull., 94(4): 783-786.

GODART, G. MS 1997. Contribution à l'étude des peuplements de la mégafaune en domaine benthique abyssal au large de l'irlande et de l'Ecosse. IFREMER, $95 \mathrm{p}$.

GORDON, J. D. M. 1979. Lifestyle and phenology in deep sea Anacanthine Teleosts. Symp. Zool. Soc. London, 44: 327-359.

GORDON, J. D. M., and S. C. SWAN. 1996. Validation of age readings from otoliths of juvenile roundnose grenadier, Coryphaenoides rupestris, a deep-water macrourid fish. J. Fish. Biol., 49(Supplement A): 289-297.

HAEDRICH R. L. and N. R. MERRETT. 1988. Summary atlas of deep-living demersal fishes in the North Atlantic Basin. J. Nat. Hist., 22: 1325-1362.

JONES, C. 2000. Fitting growth curves to retrospective sizeat-age data. Fish. Res., 46: 123-129.

KELLY, C. J., P. L. CONNOLLY, and J. J. BRACKEN. 1996. Maturity, oocyte dynamics and fecundity of the roundnose grenadier from the Rockall Trough. J. Fish. Biol., 49(Supplement A): 5-17.

1997. Age estimation, growth, maturity and distribution of the roundnose grenadier from the Rockall Trough. J. Fish. Biol., 50: 1-17.

KIMURA, D. K. 1980. Likelihood methods for the Von
Bertalanffy growth curve. Fish. Bull., 77(4): 765-776.

KOSLOW, J. A. 1996. Energetic and life-history patterns of deep-sea benthic, benthopelagic and seamount-associated fish. J. Fish. Biol., 49(Supplement A): 54-74.

KOSLOW, J. A., G. BOEHLERT, J. D. M. GORDON, R. L. HAEDRICH, P. LORANCE, and N. PARIN. 2000. Continental slope and deep-sea fisheries: implications for a fragile ecosystem. ICES J. Mar. Sci., 57(3): 548-557.

LARGE, P. A., C. HAMMER, O. A. BERGSTAD, J. D. M. GORDON, and P. LORANCE. 2003. Deep-water fisheries of the Northeast Atlantic: II Assessment and Management Approaches. J. Northw. Atl. Fish. Sci., 31: 151-163 (this volume).

LORANCE, P., and H. DUPOUY. 2001. CPUE abundance indices of the main target species of the French deepwater fishery in ICES Sub-areas V-VII. Fish. Res., 51(23): $137-149$.

LORANCE, P., H. DUPOUY, and V. ALLAIN. 2001. Assessment of the roundnose grenadier (Coryphaenoides rupestris) stock in the Rockall Trough and neighbouring areas (ICES Sub-areas V-VII). Fish. Res., 51(2$3)$ : $151-163$.

MAUCHLINE, J., and J. D. M. GORDON. 1984. Diets and bathymetric distributions of the macrourid fish of the Rockall Trough, northeastern Atlantic Ocean. Mar. Biol., 81: 107-121.

PAULY, D. 1997. Méthodes pour l'évaluation des ressources halieutiques. CEPADUES - éditions, adaptation française de J. Moreau., $288 \mathrm{p}$.

ROONEY, W., and L. BIEGLER. 1999. Incorporating joint confidence regions into design under uncertainty. Computer and Chemical Engineering, 23: 1563-1575.

TRACEY, D. M., and P. L. HORN. 1999. Background and review of ageing orange roughy (Hoplostethus atlanticus, Trachichthyidae) from New Zealand and elsewhere. N. Z. J. Mar. Freshwat. Res., 33: 67-86.

TROYANOVSKY, F. M., and S. F. LISOVSKY. 1995. Russian (USSR) fisheries research in deep waters (below $500 \mathrm{~m}$ ) in the North Atlantic. In: Deep-water fisheries of the North Atlantic oceanic slope. A. G. Hopper (ed.). Series E: Applied Sciences. Kluwer Academic Publishers, Dordrecht/Boston/London, p. 357-365.

ZIVKOV, M. T., T. A. TRICHKOVA, and G. N. RAIKOVA PETROVA. 1999. Biological reasons for the unsuitability of growth parameters and indices for comparing fish growth. Envir. Biol. Fishes, 54(1): 67-76. 
